\title{
PREPARATION OF CADMIUM TELLURIDE BY A PROGRAMMED SOLUTION GROWTH TECHNIQUE
}

\author{
B. SCHAUB, J. GALleT, A. BRUNET-JAILlY and B. PELliCiARI
}

Laboratoire d'Electronique et de Technologie de l'Informatique

Division de Cristallogénèse et de Recherche sur les Matériaux

C. E. N. G., B. P. 85,38 Grenoble, France

\begin{abstract}
Résumé. - Une nouvelle méthode de cristallisation du tellurure de cadmium est décrite. La croissance s'effectue dans un four de Bridgman à partir d'une solution riche en tellure.

On obtient ainsi des cristaux de très haute pureté de $45 \mathrm{~mm}$ de diamètre et $150 \mathrm{~mm}$ de long.

Abstract. - A new method of crystallization of cadmium telluride is described.

The growth is carried out, by normal freezing of a tellurium-rich solution, in a vertical Bridgman furnace.

Crystals of high purity ( $45 \mathrm{~mm}$ in diameter $-150 \mathrm{~mm}$ in length) are obtained with this process.
\end{abstract}

The growth is carried out in a vertical Bridgman furnace, by normal freezing of a tellurium-rich solution, at a temperature lower than the melting point of stoichiometric cadmium-telluride.
The solution is contained in a sealed quartz-crucible. The load is prepared with high purity tellurium and cadmium. Both, synthesis and dissolution are simultaneous, during heating of the furnace. Then crystalliza-

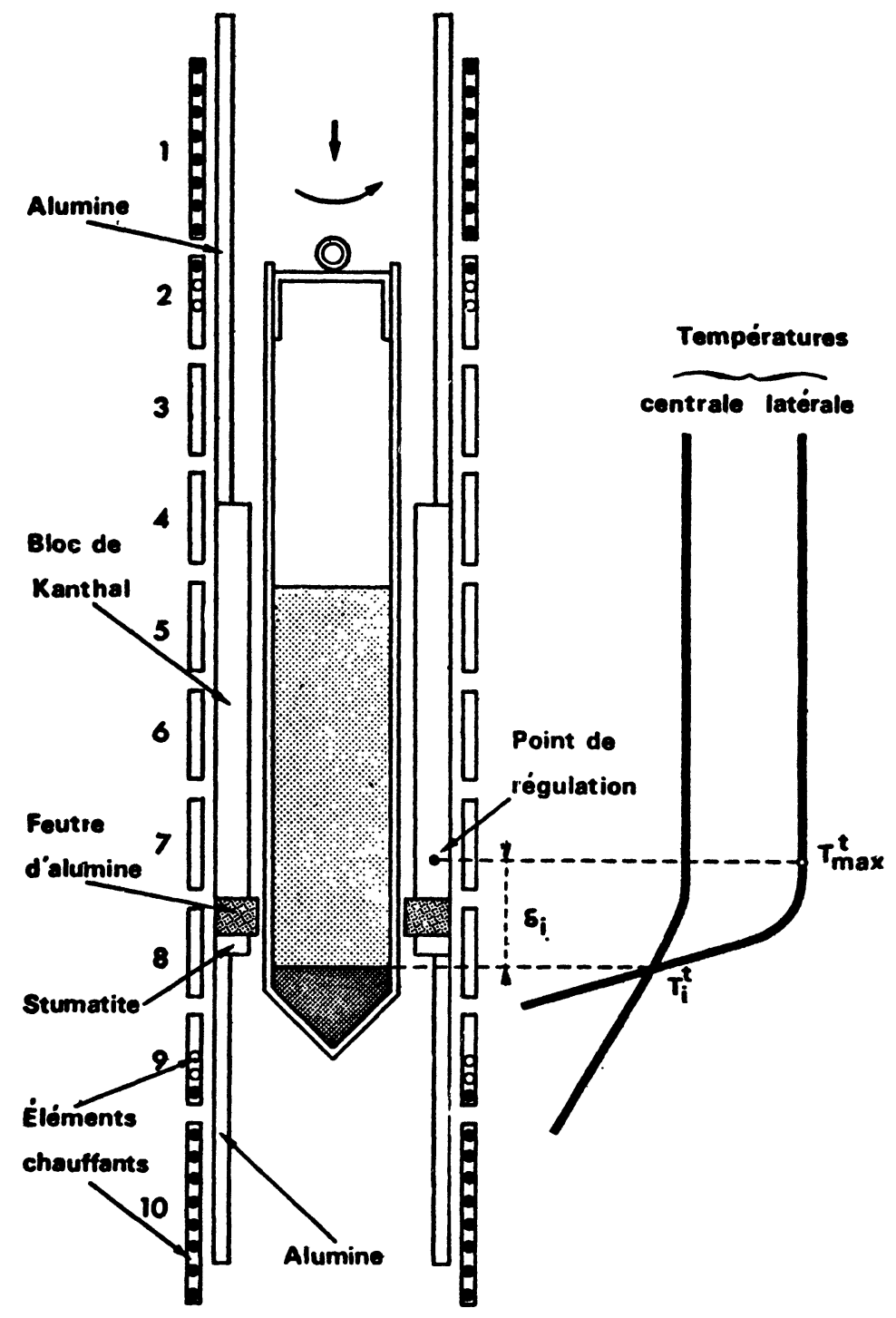

FIG. 1. 


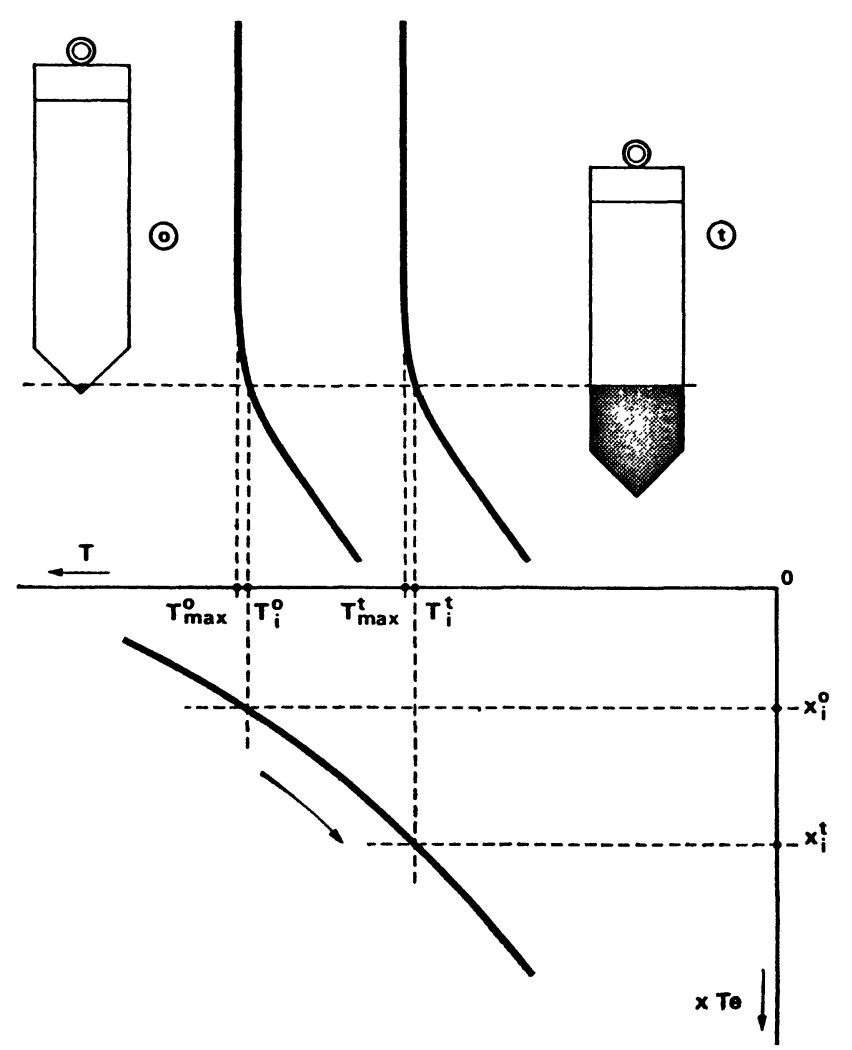

FIG. 2.

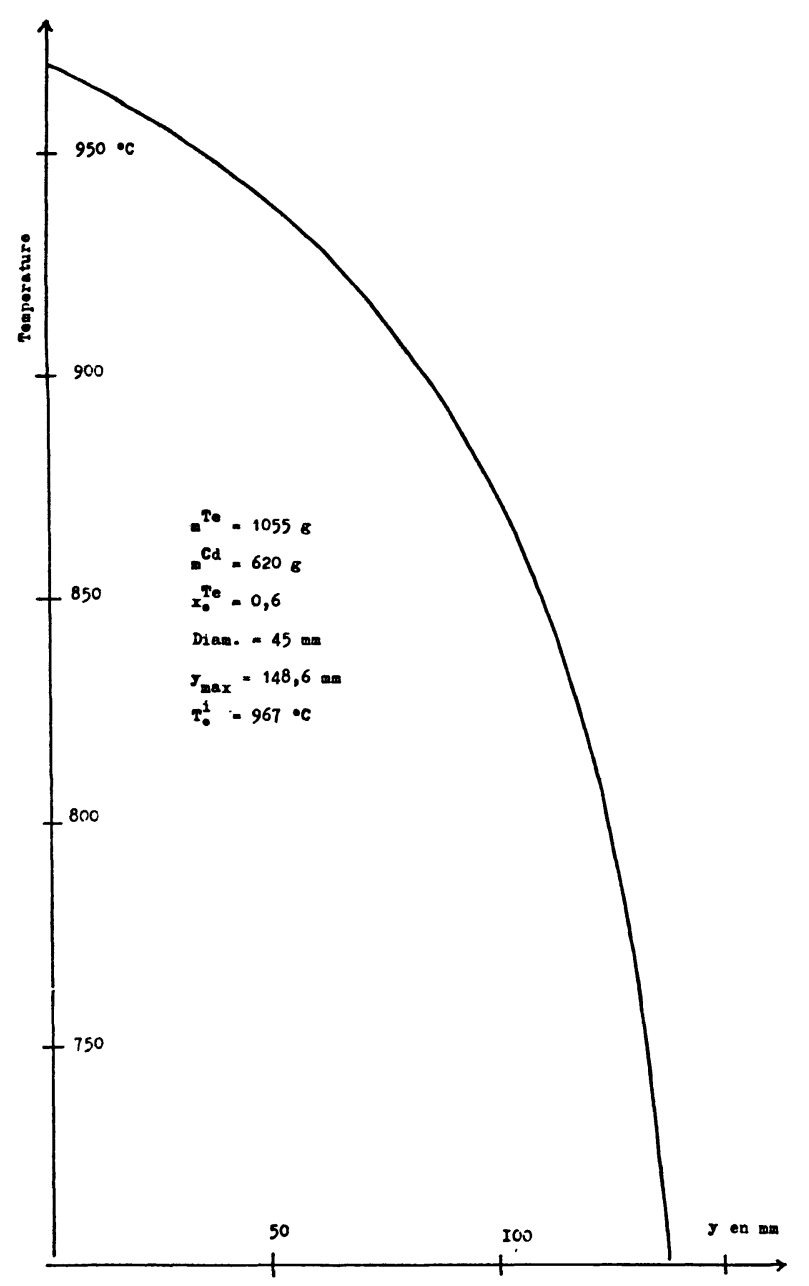

FIG. 3. tion is induced by displacement of the crystallization container, along the thermal gradient in the furnace (Fig. 1).

During crystallization, the solute concentration is continuously decreasing in the solution, and the position of crystallization interface varies in the furnace, according to the equilibrium diagram. As growth continues the growth interface moves towards the bottom of the furnace.

This fact has two undesirable effects :

- the position of the interface does not remain at the point of the furnace, where axial and transverse temperature gradients are favourable;

- the real crystallization speed cannot be imposed, since it is not the same that the speed of the container.

However, it is possible to eliminate this drawback, by suitably lowering the furnace temperature versus the crystallised length, simultaneously with the displacement of the container.

The lowering temperature programme is determined according to the solid-liquid phase diagram (Fig. 2), in relation with initial conditions : the numbers of moles of cadmium and tellurium, geometry of the container.

So, with $620 \mathrm{~g}$ of cadmium, $1055 \mathrm{~g}$ of tellurium $\left(x_{\mathrm{Te}}^{0}=0.6, T_{\mathrm{i}}^{0}=967^{\circ} \mathrm{C}\right)$ and a container of internal diameter $45 \mathrm{~mm}\left(y_{\max }=148.6 \mathrm{~mm}\right)$, the evolution of the interface temperature $\left(T_{\mathrm{i}}\right)$ with the crystallized length $(y)$ is showed figure 3 .

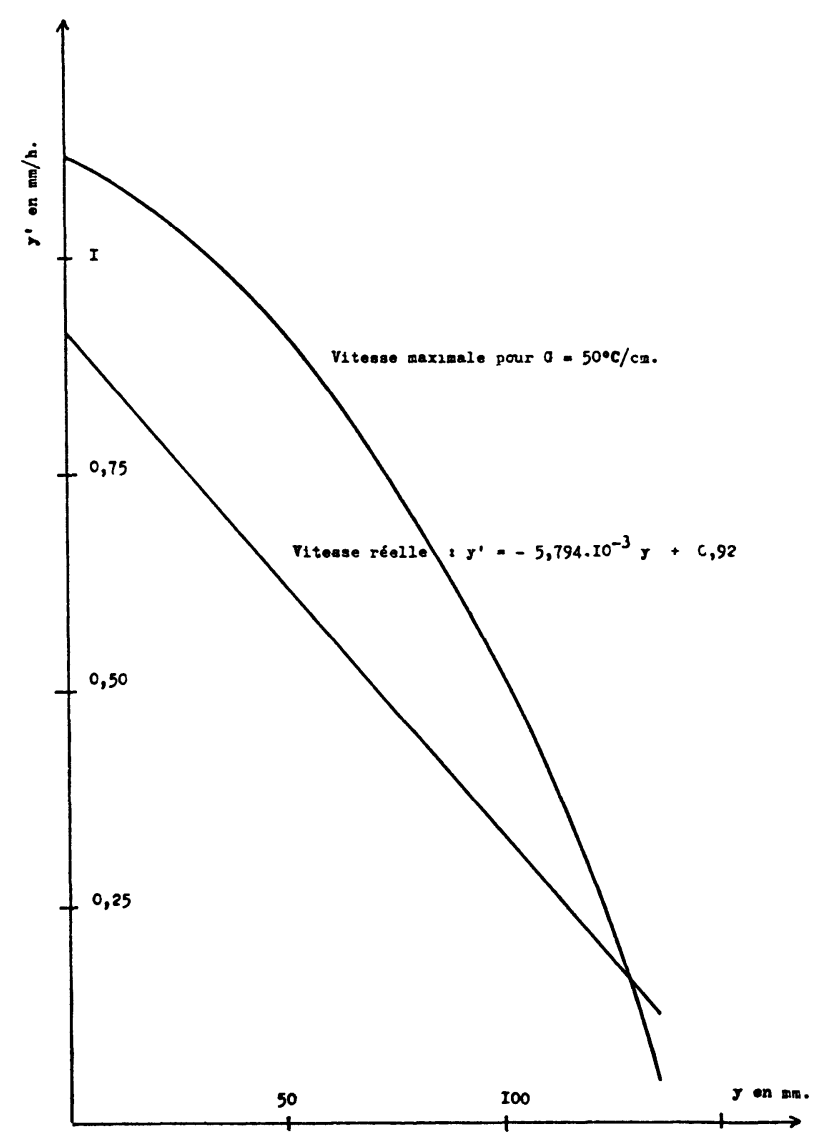

FIG. 4. 
This temperature variation is applied directly to the temperature regulator of the furnace in relation with the displacement of the container.

So that, the crystallized length is equal to the displacement of the container and the real speed of crystallization is equal to that of the container. It is possible to crystallize with a decreasing speed which is always kept lower than the critical speed of crystallization. This maximum speed can be calculated so that constitutional supercooling is avoided.

It can be seen that the growth rate is continuously decreasing with the interface temperature, and with the crystallized length (Fig. 4) ; the real speed of crystallization $y^{\prime}$ can be selected, in the shape of a linear relation :

$$
y^{\prime}=a+b y \text {. }
$$

Speed of crystallization, interface temperature, crystallized length, are then parametric functions of the time with :

$$
\frac{1}{b} \log (a+b y)-\frac{\log a}{b}=t
$$

(Fig. 5-6-7).

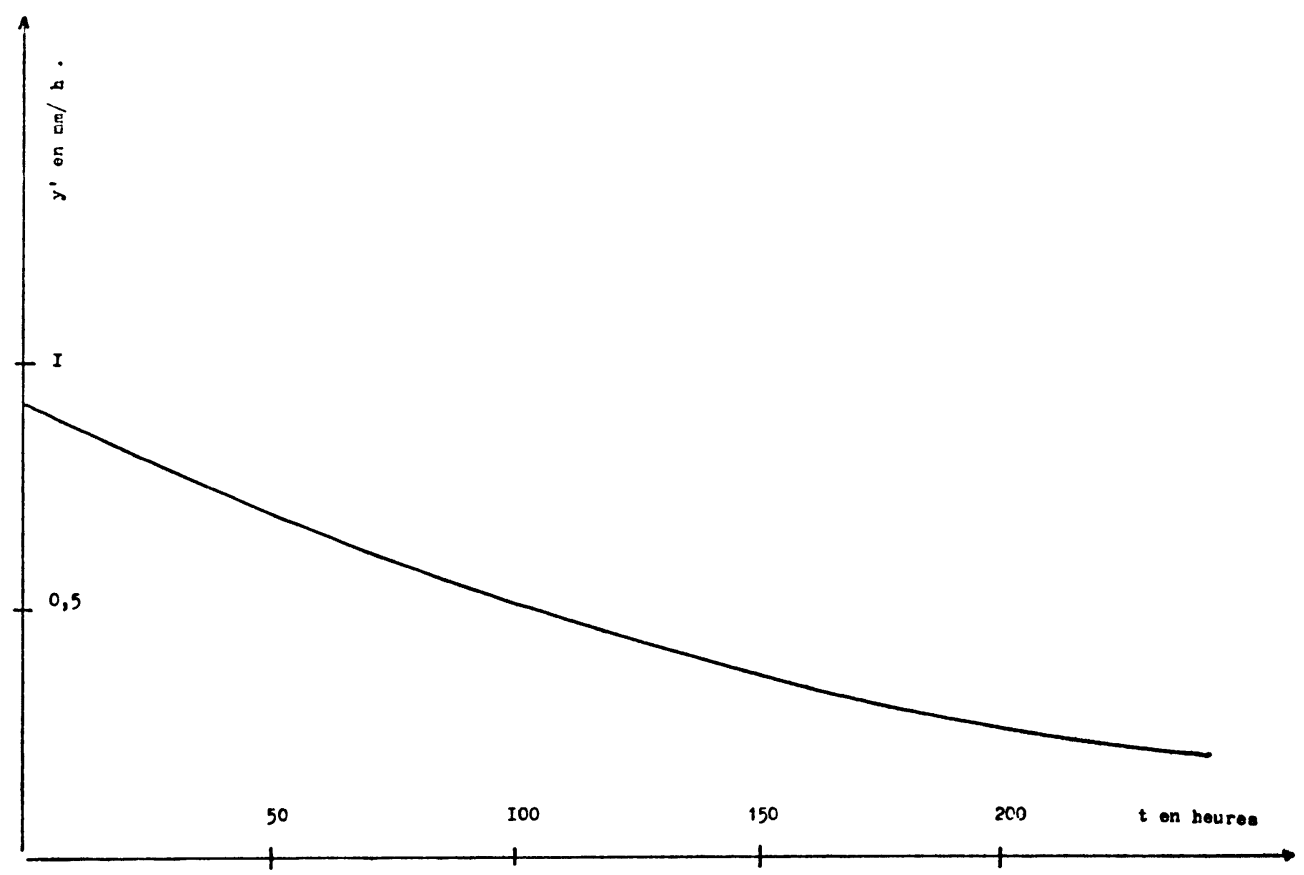

FIG. 5.

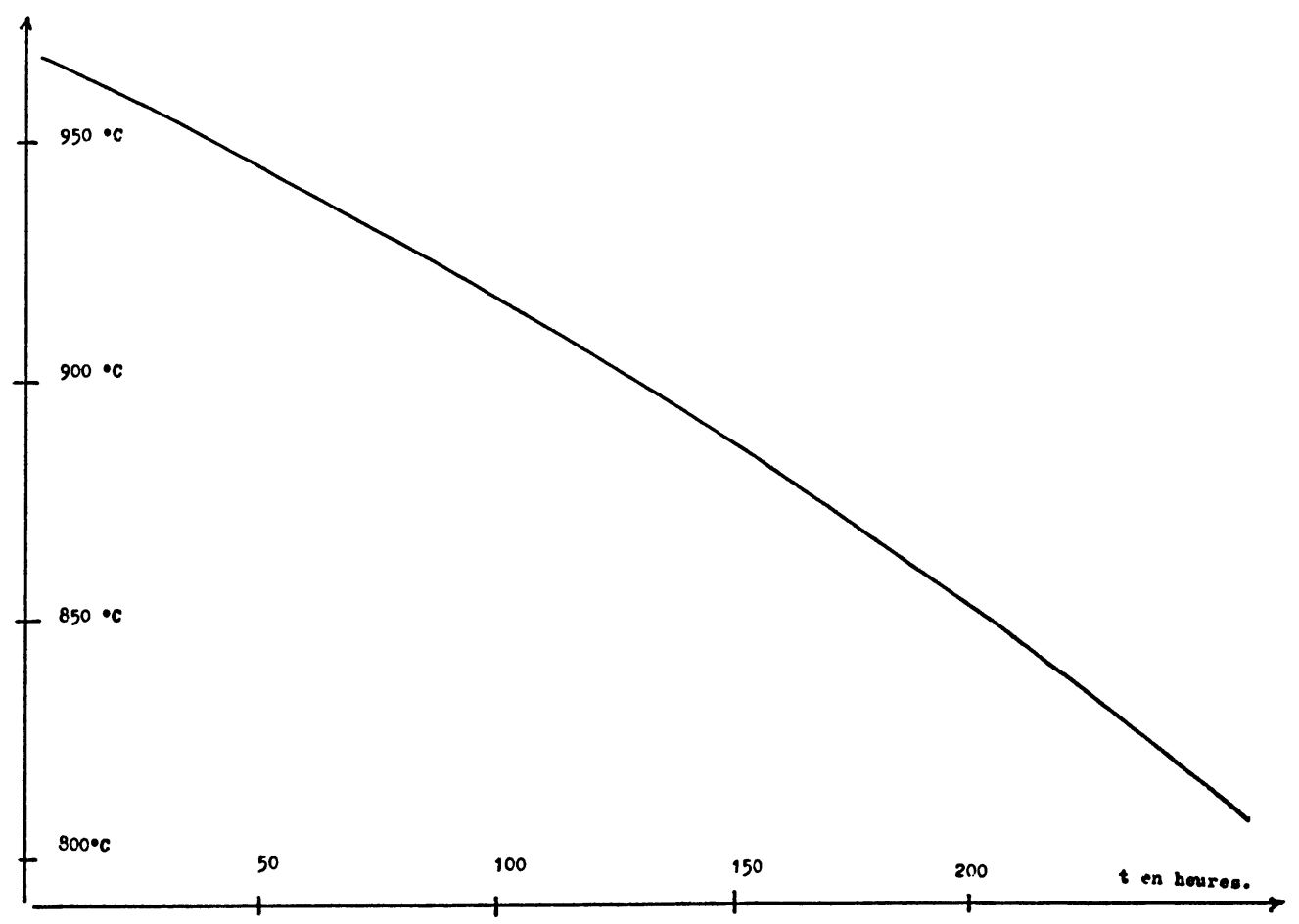

FIG. 6. 


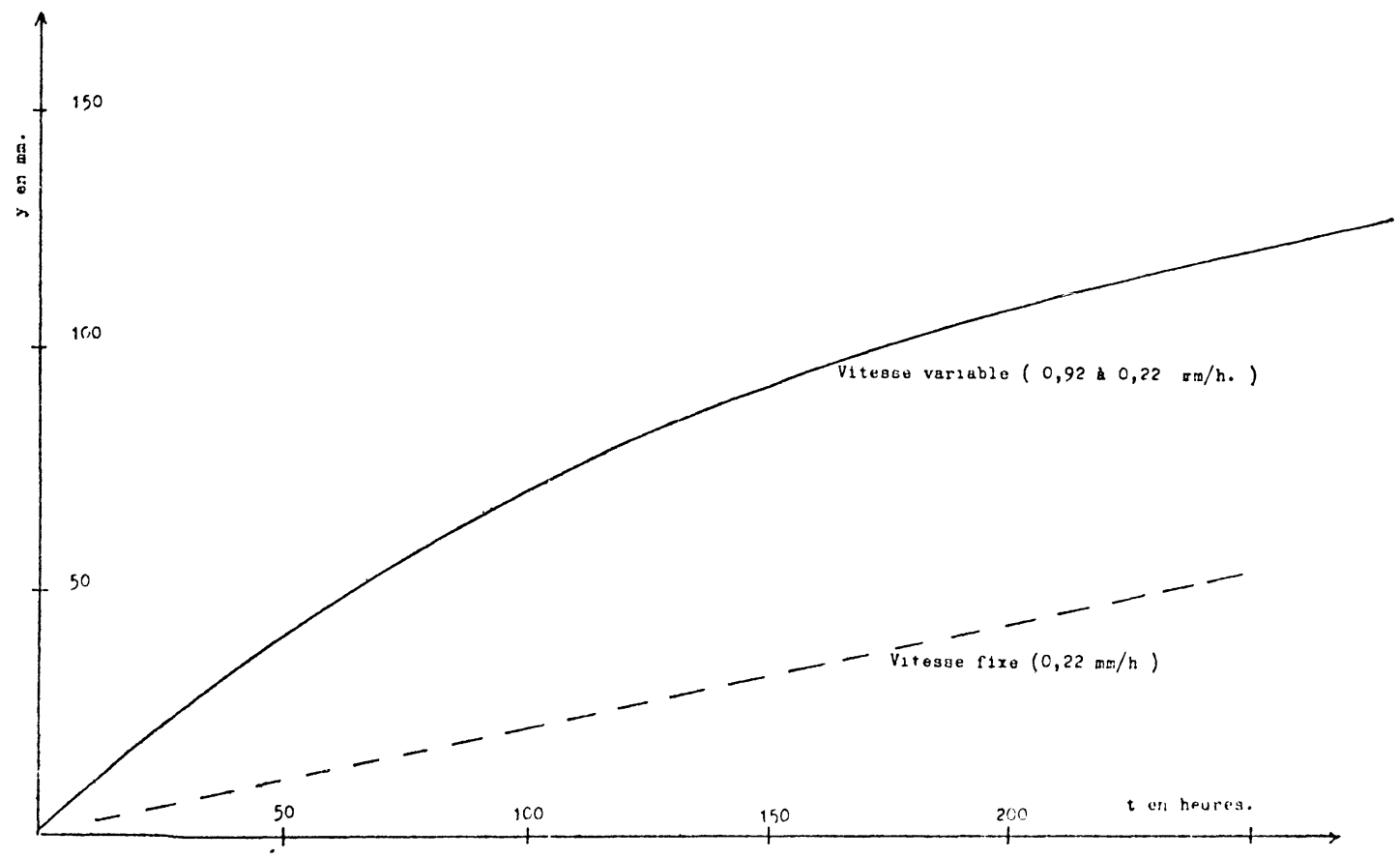

FIG. 7.

On the figure 7 the gain of time obtained with this method in contrast with a method using a constant but necessarly slow speed of crystallization, can be easily estimated.

Crystals of $45 \mathrm{~mm}$ in diameter and $150 \mathrm{~mm}$ in length are obtained with this process.
The purity of these ingots is very high and with convenient doping it can be a good material for the realization of infrared windows or light modulators on substracts for epitaxy. Up to now, the nuclear detection efficacity of these crystals is not as good as that of THM crystals. 